\title{
Growth Accelerated, CTCAE
}

National Cancer Institute

\section{Source}

National Cancer Institute. Growth Accelerated, CT CAE. NCI Thesaurus. Code C143520.

A disorder characterized by greater growth than expected for age. 